\title{
Identification of related long non-coding RNAs and mRNAs in subclinical hypothyroidism complicated with type 2 diabetes by transcriptome analysis - a preliminary study
}

\author{
Qiang Jiang ${ }^{1-3}$, Lizhi Sun ${ }^{3}$, Yong Lu', Shuyi Han ${ }^{3}$, Lulu Hou', Kai Lou', Jianting Li', Lulu Wang', \\ Shuguang Pang ${ }^{1}$ \\ ${ }^{1}$ Department of Endocrinology, Jinan Central Hospital, Cheeloo College of Medicine, Shandong University, Jinan, China \\ ${ }^{2}$ Department of Endocrinology, Jinan Central Hospital Affliated to Shandong First Medical University, Jinan, China \\ ${ }^{3}$ Central Laboratory, Jinan central Hospital, Cheeloo College of Medicine, Shandong University, Jinan, China
}

\begin{abstract}
Introduction: The pathology mechanism of subclinical hypothyroidism and subclinical hypothyroidism complicated with type 2 diabetes remained uncertain. We aimed to find potential related long non-coding RNAs (lncRNAs) and mRNAs in the above diseases.

Material and methods: Transcriptome sequencing was performed in three patients with subclinical hypothyroidism (S), three patients with subclinical hypothyroidism complicated with type 2 diabetes (SD), and three healthy controls (N). Differentially expressed mRNAs (DEmRNAs) and differentially expressed lncRNAs (DElncRNAs) were screened in S vs. N, SD vs. N, and SD vs. S group, and the nearby and co-expressed DEmRNAs of DElncRNAs were screened in S vs. N and SD vs. N. Moreover, functional analysis of DEmRNAs was then performed by Metascape.

Results: In total, 465, 1058, and 943 DEmRNAs were obtained in S vs. N, SD vs. N, SD vs. S, respectively, and 191 overlapping genes were obtained in S vs. N and SD vs. N group. Among which, LAIR2, PNMA6A, and SFRP2 were deduced to be involved in subclinical hypothyroidism, and GPR162, APOL4, and ANK1 were deduced to be associated with subclinical hypothyroidism complicated with type 2 diabetes. A total of 50, 100, and 88 DElncRNAs were obtained in S vs. N, SD vs. N and SD vs. S, respectively. Combining with the interaction network of DElncRNA-DEmRNA, PAX8-AS1, co-expressed with KIR3DL1, was identified to function in subclinical hypothyroidism, and JHDM1D-AS1, co-expressed with ANK1, was deduced to play a role in subclinical hypothyroidism complicated with type 2 diabetes. Conclusions: Dysfunctional lncRNAs and mRNAs may be involved in the development of subclinical hypothyroidism and subclinical hypothyroidism complicated with type 2 diabetes. (Endokrynol Pol 2020; 71 (3): 213-226)
\end{abstract}

Key words: subclinical hypothyroidism; subclinical hypothyroidism complicated with type 2 diabetes; IncRNAs; mRNAs

\section{Introduction}

Hypothyroidism, as a result of insufficient thyroid hormone secretion, leads to a decline in the body's metabolic activity and other clinical syndromes [1]. Clinical hypothyroidism and subclinical hypothyroidism $(\mathrm{SCH})$ were identified according to the degree of thyroid function reduction. $\mathrm{SCH}$ was biochemically defined as an elevated serum thyroid stimulating hormone (TSH) level, whereas the stable serum free T4 level was within the population reference range. Patients with $\mathrm{SCH}$ varied among populations and ranged from $3 \%$ to $15 \%$, with a higher incidence associated with increasing age, female sex, and suboptimal iodine status [2]. The $\mathrm{SCH}$ was distinguished by the degree of TSH in clinical diagnosis. TSH normal laboratory reference range was $0.3-5.0 \mathrm{mIU} / \mathrm{L}$, and higher than $5 \mathrm{mIU} / \mathrm{L}$ was regarded as $\mathrm{SCH}[2-5]$. However, the TSH range defining $\mathrm{SCH}$ remained elusive [3], and few molecular mechanisms were investigated in subclinical hypothyroidism. Therefore, a large number of researchers devoted time to the discovery biomarkers and molecular characters in $\mathrm{SCH}$.

Although many patients with $\mathrm{SCH}$ were asymptomatic, some studies have shown a close relationship between $\mathrm{SCH}$ and several diseases, including heart failure [6], depression [7], atherosclerosis [8], as well as abortion [9]. It is reported that the prevalence of hypothyroidism in diabetics varies from $0.2 \%$ to $1.7 \%$ [10]. However, a cross-sectional study showed that the prevalence of $\mathrm{SCH}$ was similar between patients with diabetes mellitus and healthy controls [11]. Therefore, we analysed molecular characters in patients with $\mathrm{SCH}$ (S), patients with SCH complicated with type 2 diabetes (SD), and healthy controls (N) by transcriptome sequencing to explore whether type 2 diabetes was associated with $\mathrm{SCH}$. 
Long non-coding RNAs (lncRNAs) are defined as a heterogeneous class of non-coding transcripts $>200$ base pairs in length $[12,13]$. It has been demonstrated that lncRNAs plays key roles in the regulation of mRNA splicing, transcription, translation, import, export and stability [14]. In view of the important roles of lncRNAs, we aimed to identify the key mRNA, lncRNA, and mRNA-lncRNA co-expressed pairs, and performed functional enrichment analysis to reveal the pathogenesis of SCH and SCH complicated with type 2 diabetes. Our study may be helpful in understanding the molecular changes of identified lncRNAs and mRNAs in SCH and SCH complicated with diabetes.

\section{Material and methods}

\section{Subjects and blood sampling}

Study samples consisted of three patients with subclinical hypothyroidism (S), three patients with subclinical hypothyroidism complicated with type 2 diabetes (SD), and three healthy control subjects $(\mathrm{N})$. The inclusion criteria of subclinical hypothyroidism were as follows: TSH $>4.0 \mathrm{mIU} / \mathrm{L}$, and normal serum free triiodothyronine FT3 and free thyroxine FT4 levels. The exclusion criteria of subclinical hypothyroidism were as follows: no intermittent claudication; refractory ulcers and gangrene of lower extremities; type 1 diabetes; acute complications of diabetes; cardiac insufficiency; severe infection; severe liver and kidney disease; malignant tumours; previous history of thyroid disease; history of blood transfusion in the past six months; and pregnant or lactating patients. The inclusion criteria of subclinical hypothyroidism complicated with type 2 diabetes were as follows: TSH $>4.0 \mathrm{mIU} / \mathrm{L}$; normal serum free triiodothyronine (FT3) and free thyroxine (FT4) levels; and type 2 diabetes. The exclusion criteria of subclinical hypothyroidism complicated with type 2 diabetes were as follows: no intermittent claudication; refractory ulcers and gangrene of lower extremities; cardiac insufficiency; severe infection; severe liver and kidney disease; malignant tumours; previous history of thyroid disease; history of blood transfusion in the past six months; and pregnant or lactating patients. The inclusion criteria of the healthy population control group were as follows: age as close as possible to the patients in the disease group; no history of thyroid disease; and no history of type 2 diabetes. In addition to the correct diagnosis, the interview provided information including all participates' age, gender, TSH value, and family history. Detailed clinical information of all these participants is shown in Table 1. In addition, statistical analysis of tobacco smoking, alcohol drinking, diet, and medicaments in SD and S compared with controls are shown in supplementary Table S1 and supplementary Table S2, respectively. There was no significant difference in terms of the above clinical index in SD and S compared with controls. A whole blood sample ( $2.5 \mathrm{~mL}$ per BD tube) for RNA-Seq was taken from the cubital vein of the arm at room temperature. Then, the blood sample was inverted slowly for mixture 8-10 times. After vertical placement at $18-25^{\circ} \mathrm{C}$ for three days, the blood samples were stored at $2-8^{\circ} \mathrm{C}$ for five days, then at $-20^{\circ} \mathrm{C}$ for 24 hours, and finally transferred to $-80^{\circ} \mathrm{C}$ for long-term storage (50 months).

This study was approved by the Ethics Committee of Jinan Central Hospital (Series number: 2018-103). Signed informed consent was obtained from all the participants. This research complied with the principles of the Declaration of Helsinki.

\section{RNA isolation, library construction, and sequencing}

Total RNA was extracted from blood samples by using by TRIzol reagent (Invitrogen, Carlsbad, CA, USA) according to the manufacturer's instructions. A Nanodrop ND-2000 spectrophotometer (Thermo Scientific, Wilmington, DE, USA) and 2\% agarose gel were used to check the concentration and purity of RNA. An Agilent 2100 Bioanalyzer (Agilent Technologies, Palo Alto, CA) was used to obtain the RIN (RNA integrity number) value (from 0 to 10 ). The larger the value, the better and more complete the RNA. Only RNA samples with RIN $>7$ can be used for RNA sequencing.

A library for high-throughput sequencing of lncRNA and mRNA was constructed by qualified RNA. Firstly, we removed the ribosomal RNA from total RNA and then randomly fragmented RNA into about 200 base pairs. Secondly, the first cDNA strand was synthesised by RNA fragments primed with random hexamer primers, and then the second cDNA strand was synthesised with dUTP instead of dTTP. Finally, after purification by the Qiaquick PCR purification kit, end repair, $3^{\prime}$ end adenylation, adapter ligation, UNG digestion, polymerase chain reaction (PCR), and gel extraction, the library construction was completed. The cDNA library was qualified by an Agilent 2100 Bioanalyzer and ABI StepOnePlus Real-TimePCR System and then sequenced by Illumina Hiseq x-ten machine.

\section{Quality control of raw data and clean-reads mapping}

Clean reads were obtained from the raw reads by removing lowquality sequences $(<\mathrm{Q} 20)$ and shorter sequences $<20 \mathrm{bp}$ and ambiguous ' $\mathrm{N}$ ' nucleotides (with the ratio of ' $\mathrm{N}$ ' > 10\%) using

Table 1. Clinical information of participants

\begin{tabular}{|c|c|c|c|c|c|c|c|c|c|}
\hline Group & Number & Gender & Age [year] & $\begin{array}{c}\text { Weight } \\
\text { [kg] }\end{array}$ & $\begin{array}{c}\text { TSH } \\
{[\mathrm{mIU} / \mathrm{L}]}\end{array}$ & $\begin{array}{c}\text { FT3 } \\
{[\mathrm{pmol} / \mathrm{L}]}\end{array}$ & $\begin{array}{c}\text { FT4 } \\
\text { [pmol/L] }\end{array}$ & $\begin{array}{c}\text { FBG } \\
{[\mathrm{mmol} / \mathrm{L}]}\end{array}$ & $\begin{array}{l}\text { Family } \\
\text { history }\end{array}$ \\
\hline \multirow{3}{*}{ S } & 1 & Female & 56 & 65 & 5.61 & 4.88 & 16.25 & 5.6 & No \\
\hline & 2 & Female & 61 & 70 & 5.06 & 4.54 & 14.5 & 5 & No \\
\hline & 3 & Male & 58 & 65 & 17.3 & 4.74 & 12.07 & 5.1 & No \\
\hline \multirow{3}{*}{ SD } & 1 & Female & 49 & 59 & 7.01 & 4.05 & 14.96 & 8.5 & No \\
\hline & 2 & Male & 60 & 78 & 6.54 & 4.37 & 15.1 & 8.1 & No \\
\hline & 3 & Male & 56 & 90 & 7.39 & 4.92 & 19.66 & 8.8 & No \\
\hline \multirow{3}{*}{ Control } & 1 & Female & 46 & 64 & 1.4 & 3.8 & 15.5 & 5.3 & No \\
\hline & 2 & Male & 48 & 79.7 & 1.16 & 5.82 & 19.93 & 4.6 & No \\
\hline & 3 & Female & 46 & 64 & 0.56 & 4.32 & 15.11 & 4.8 & No \\
\hline
\end{tabular}

S — subclinical hypothyroidism; SD — subclinical hypothyroidism complicated with diabetes; TSH — thyroid-stimulating hormone; FT3 — free triiodothyronine; FT4 — free thyroxine; FBG — fasting blood glucose 
Table 2. Clean reads and genome mapping

\begin{tabular}{lcccccc}
\hline Sample & Clean reads & $\mathbf{0 2 0}(\%)$ & GC $(\%)$ & Aligned pairs & Concordant pair & Concordant pair rate \\
\hline S & $67,426,220$ & $96.06 \%$ & $51.32 \%$ & 28750021 & 28291823 & $83.80 \%$ \\
\hline S & $69,617,720$ & $96.61 \%$ & $52.25 \%$ & 28229932 & 27718166 & $81.90 \%$ \\
\hline S & $68,231,638$ & $96.21 \%$ & $53.48 \%$ & 28004235 & 27437375 & $80.10 \%$ \\
\hline SD & $67,226,002$ & $96.68 \%$ & $50.37 \%$ & 27563225 & 26914177 & $79.80 \%$ \\
\hline SD & $68,029,786$ & $96.39 \%$ & $49.37 \%$ & 29097641 & 28719125 & $82.50 \%$ \\
\hline SD & $66,704,268$ & $96.69 \%$ & $51.02 \%$ & 28100877 & 26768940 & $78.50 \%$ \\
\hline Control & $67,539,910$ & $97.01 \%$ & $51.13 \%$ & 28121092 & 27631140 & $82.20 \%$ \\
\hline Control & $67,726,216$ & $96.57 \%$ & $49.26 \%$ & 28249243 & 27775680 & $81.70 \%$ \\
\hline Control & $68,480,746$ & $95.96 \%$ & $47.46 \%$ & 27944572 & 27439744 & $82.30 \%$ \\
\hline
\end{tabular}

Cutadapt software (http://cutadapt.readthedocs.io). After trimming the high-quality clean reads were aligned with the human reference genome GRCh38 by TopHat (http://tophat.cbcb.umd.edu/), which can be downloaded in NCBI, UCSC, RefSeq, and Ensembl.

\section{Identification of differentially expressed $m R N A s$ and $\operatorname{lncRNAs}$}

Expression quantitation and standardised output were performed by Cuffquan. Differentially expressed mRNAs and lncRNAs between patients with different diseases and healthy persons ( $\mathrm{S}$ vs. N, SD vs. N and S vs. SD) were identified by Cuffdiff (http://cufflinks. cbcb.umd.edu/) ( $p$ value $<0.05$ ). In addition, shared genes were identified in the intersection of the $\mathrm{S}$ and SD groups.

\section{Identification of cis-regulated $m R N A s$}

\section{and co-expressed mRNAs of lncRNAs}

In order to explore the cis-regulated mechanism of lncRNAs, the nearby mRNAs were identified within a $100 \mathrm{~kb}$ window up- or down-stream of DElncRNAs in $\mathrm{S}$ vs. $\mathrm{N}$ and $\mathrm{S}$ vs. N groups. Moreover, the correlation between DElncRNA and DEmRNA in the two groups ( $\mathrm{S}$ vs. N, SD vs. N) was analysed by Pearson correlation coefficient. The DElncRNA-DEmRNA pairs were obtained when $|\mathrm{r}|>0.95$ and $\mathrm{p}<0.05$, and the DElncRNA-DEmRNA interaction network was then constructed by Cytoscape (http://www. cytoscape.org/).

\section{Functional analysis of differentially expressed mRNAs and mRNA-lncRNA co-expressed pairs}

Gene ontology (GO) and Kyoto Encyclopaedia of Genes and Genomes (KEGG) molecular pathway enrichment analysis of DEmRNAs and mRNA-lncRNA co-expressed pairs in three groups (S vs. N, SD vs. N and SD vs. S) were performed by Metascape (http://metascape.org/gp/index.html) under the threshold of pvalue $<0.05$

\section{Results}

\section{Transcriptome sequencing, filtering, and annotation}

After removing the low-quality reads, $6.74 \times 10^{7}$, $6.96 \times 10^{7}$, and $6.82 \times 10^{7}$ reads were obtained in three hypothyroidism samples (S), $6.72 \times 10^{7}, 6.80 \times 10^{7}$, and $6.67 \times 10^{7}$ reads were obtained in three type 2 diabetes and concomitant hypothyroidism samples (SD), and $6.75 \times 10^{7}, 6.77 \times 10^{7}$, and $6.85 \times 10^{7}$ reads were obtained in three healthy samples (N) (Tab. 2). All of the clean reads were aligned with the human reference genome GRCh38. The concordant pair rates of all samples were above $78 \%$.

\section{Identification of DEmRNAs and DElncRNAs}

Compared to healthy controls, 465 DEmRNAs (240 up-regulated and 225 down-regulated) were identified in the $S$ group $(p<0.05)$. The top 20 DEmRNAs between $\mathrm{S}$ and $\mathrm{N}$ are shown in Table 3. Hierarchical clustering of the top 100 DEmRNAs between $S$ and N is shown in Figure 1A. Compared to healthy controls, 1058 DEmRNAs (874 up-regulated and 184 down-regulated) were identified in the SD group $(p<0.05)$. The top 20 DEmRNAs between SD and $\mathrm{N}$ are shown in Table 4. Hierarchical clustering of the top 100 DEmRNAs between SD and $\mathrm{N}$ is shown in Figure 1B. Compared to the $\mathrm{S}$ group, 943 DEmRNA (797 up-regulated and 146 down-regulated) were identified in the SD group $(p<0.05)$. The top 20 DEmRNAs between SD and S are shown in Table 5. In addition, the intersection of two groups ( $\mathrm{S} v s . \mathrm{N}, \mathrm{SD}$ vs. N) of DEmRNAs was performed by Venn diagrams (Fig. 2). 274 S-specific DEmRNAs, 867 SD-specific DEmRNAs, and 191 overlapping DEmRNAs were identified.

Compared to healthy controls, 50 DElncRNAs (25 up-regulated and 25 down-regulated) were identified in the $S$ group $(p<0.05)$. The top 20 DElncRNAs between $\mathrm{S}$ and $\mathrm{N}$ are shown in Table 6. Hierarchical clustering of the top 100 DElncRNAs between $S$ and N is shown in Figure 3A. Compared to healthy controls, 100 DElncRNAs (83 up-regulated and 17 down-regulated) were identified in the SD group $(p<0.05)$. The top 20 DElncRNAs between SD and N are shown in Table 7. Hierarchical clustering of the top 100 DElncRNAs between SD and N is shown in Figure 3B. Compared to the $\mathrm{S}$ group, 88 DElncRNAs (70 up-regulated and 18 down-regulated) were identified in the SD group (Tab. 8). The top 20 DElncRNAs between SD and S are shown in Table 6. 
Table 3. Top 20 significantly differentially expressed mRNAs in $S$ vs. $N$ group

\begin{tabular}{|c|c|c|c|c|}
\hline Gene & Locus & Log2 (fold change) & $\mathrm{p}$ value & Up/Down \\
\hline ARHGEF10 & chr8:1823975-1958641 & -3.03847 & $5.00 \mathrm{E}-05$ & Down \\
\hline SLC2A14 & chr12:7812511-7891196 & -2.41504 & $5.00 \mathrm{E}-05$ & Down \\
\hline HDC & chr15:50241944-50266049 & -2.3321 & $5.00 \mathrm{E}-05$ & Down \\
\hline GATA2 & chr3:128479421-128503207 & -2.23534 & $5.00 \mathrm{E}-05$ & Down \\
\hline MZB1 & chr5:139387567-139389916 & -1.70994 & $5.00 \mathrm{E}-05$ & Down \\
\hline SLC45A3 & chr1:205657850-205690435 & -1.68527 & $5.00 \mathrm{E}-05$ & Down \\
\hline HRH4 & chr18:24460567-24487427 & -1.56157 & $5.00 \mathrm{E}-05$ & Down \\
\hline TMTC1 & chr12:29500812-29784759 & -1.39185 & $5.00 \mathrm{E}-05$ & Down \\
\hline SLC4A10 & chr2:161624334-161985276 & -1.27193 & $5.00 \mathrm{E}-05$ & Down \\
\hline BATF2 & chr11:64987944-64997045 & -1.21358 & $5.00 \mathrm{E}-05$ & Down \\
\hline KIR2DL1 & chr19:54769207-54784326 & 1.50381 & $5.00 \mathrm{E}-05$ & Up \\
\hline KIR3DL2 & chr19:54850318-54867215 & 1.54403 & $5.00 \mathrm{E}-05$ & Up \\
\hline KIR2DL3 & chr19:54738508-54753052 & 1.55242 & $5.00 \mathrm{E}-05$ & Up \\
\hline NINL & chr20:25452696-25585531 & 1.57776 & $5.00 \mathrm{E}-05$ & Up \\
\hline KIR2DS4 & chr19:54832675-54848569 & 1.7037 & $5.00 \mathrm{E}-05$ & Up \\
\hline LAIR2 & chr19:54502796-54510693 & 1.94618 & $5.00 \mathrm{E}-05$ & Up \\
\hline KIR3DL1 & chr19:54816437-54830778 & 1.96698 & 5.00E-05 & Up \\
\hline KLRC2 & chr12:10430598-10435993 & 2.38573 & $5.00 \mathrm{E}-05$ & Up \\
\hline RAP1GAP & chr1:21596214-21669444 & 3.10314 & $5.00 \mathrm{E}-05$ & Up \\
\hline C4BPA & chr1:207104231-207159509 & 3.73471 & 5.00E-05 & Up \\
\hline
\end{tabular}

\section{A}

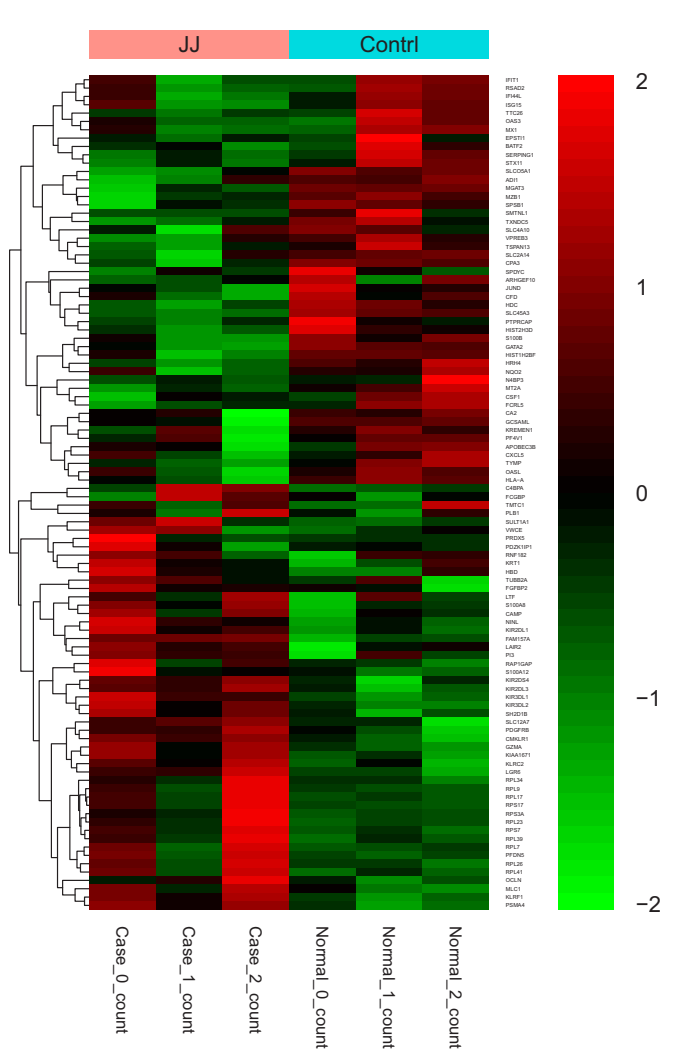

B

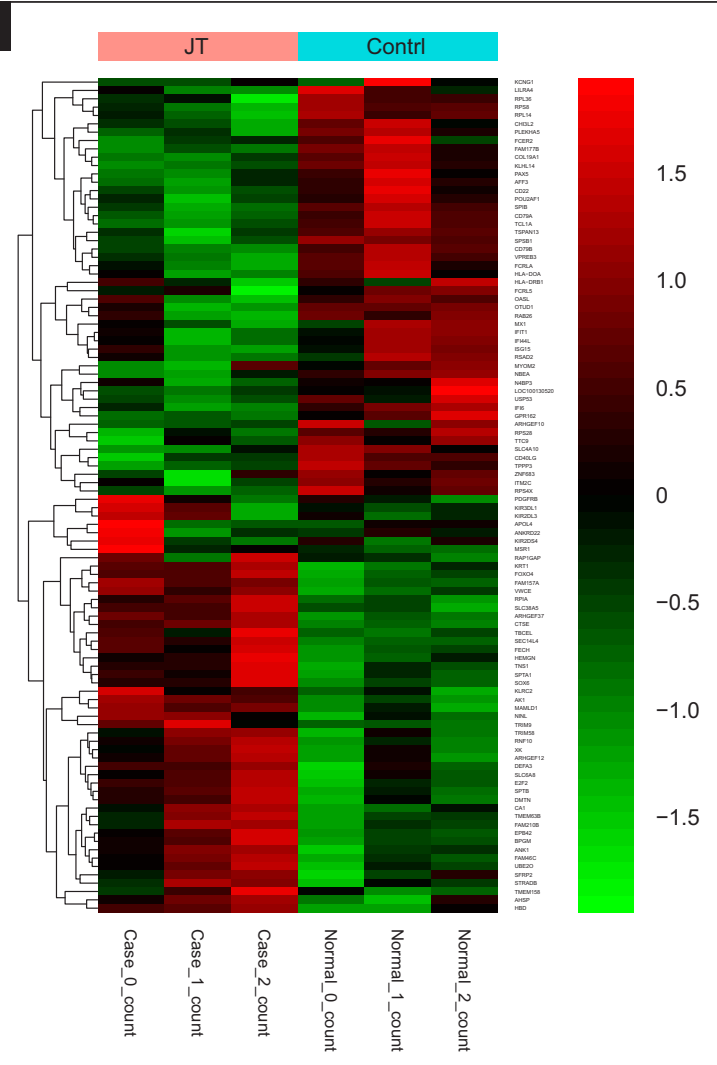

Figure 1. Hierarchical clustering analysis of top 100 DEmRNAs between $S$ and normal samples $(\boldsymbol{A})$, SD and normal samples (B). Row and column represented DEmRNAs and samples, respectively. JJ: S group; JT: SD group 
Table 4. Top 20 significantly differentially expressed mRNAs in SD vs. $N$ group

\begin{tabular}{lcccc}
\hline Gene & Locus & Log2 (fold change) & p value & Up/Down \\
\hline KLRC2 & chr12:10430598-10435993 & 3.54759 & $5.00 \mathrm{E}-05$ & Up \\
\hline KRT1 & chr12:52674735-52680407 & 3.46571 & $5.00 \mathrm{E}-05$ & Up \\
\hline AP0L4 & chr22:36189127-36204833 & 3.1522 & $5.00 \mathrm{E}-05$ & Up \\
\hline RAP1GAP & chr1:21596214-21669444 & 2.82506 & $5.00 \mathrm{E}-05$ & Up \\
\hline ANKRD22 & chr10:88802729-88851975 & 2.45375 & $5.00 \mathrm{E}-05$ & Up \\
\hline ARHGEF37 & chr5:149552048-149634968 & 2.33351 & $5.00 \mathrm{E}-05$ & Up \\
\hline FAM157A & chr3:198152154-198198958 & 2.11608 & $5.00 \mathrm{E}-05$ & Up \\
\hline FAM46C & chr1:117605981-117628389 & 1.97119 & Up \\
\hline ANK1 & chr8:41653224-41896762 & 1.9512 & $5.00 \mathrm{E}-05$ & Up \\
\hline SFRP2 & chr4:153780589-153789076 & 1.9425 & $5.00 \mathrm{E}-05$ & Up \\
\hline IFI6 & chr1:27666060-27672213 & -0.85871 & $5.00 \mathrm{E}-05$ & Down \\
\hline CD79B & chr17:63928737-63932344 & -0.94624 & $5.00 \mathrm{E}-05$ & Down \\
\hline IFIT1 & chr10:89392545-89406487 & -1.01546 & $5.00 \mathrm{E}-05$ & Down \\
\hline CD79A & chr19:41877119-41881372 & -1.03601 & $5.00 \mathrm{E}-05$ & Down \\
\hline RPS28 & chr19:8321499-8322396 & -1.07535 & $5.00 \mathrm{E}-05$ & Down \\
\hline GPR162 & chr12:6821796-6827418 & -1.26035 & $5.00 \mathrm{E}-05$ & Down \\
\hline TCL1A & chr14:95694159-95714196 & -1.54492 & $5.00 \mathrm{E}-05$ & Down \\
\hline MYOM2 & chr8:2045042-2145456 & -1.57458 & $5.00 \mathrm{E}-05$ & Down \\
\hline SLC4A10 & chr2:161624334-161985276 & -1.72178 & $5.00 \mathrm{E}-05$ & Down \\
\hline LOC100130520 & chr17:74557228-74567512 & -1.85946 & $5.00 \mathrm{E}-05$ & Down \\
\hline
\end{tabular}

Table 5. Top 20 significantly differentially expressed mRNAs in SD vs. S group

\begin{tabular}{lcccc}
\hline Gene & Locus & Log2 (fold change) & p value & Up/Down \\
\hline LOC100130520 & chr17:74557228-74567512 & -1.99776 & $5.00 E-05$ & Down \\
\hline LAIR2 & chr19:54502796-54510693 & -1.71188 & $5.00 E-05$ & Down \\
\hline GPR162 & chr12:6821796-6827418 & -1.52603 & $5.00 E-05$ & Down \\
\hline ZNF683 & chr1:26361631-26374520 & -1.40167 & $5.00 E-05$ & Down \\
\hline RPL26 & chr17:8377515-8383247 & -1.39417 & $5.00 E-05$ & Down \\
\hline TCL1A & chr14:95694159-95714196 & -1.18088 & $5.00 E-05$ & Down \\
\hline RPS26 & chr12:56041901-56044223 & -1.14595 & $5.00 E-05$ & Down \\
\hline RPS3A & chr4:151099572-151104652 & -1.05839 & $5.00 E-05$ & Down \\
\hline SH2D1B & chr1:162395265-162412138 & -1.0006 & $5.00 E-05$ & Down \\
\hline RPS28 & chr19:8321499-8322396 & -0.9618 & $5.00 E-05$ & Down \\
\hline PNMA6A & chrX:153072413-153075019 & 3.89001 & $5.00 E-05$ & Up \\
\hline IL31RA & chr5:55840333-55922854 & 3.47808 & $5.00 E-05$ & Up \\
\hline HDC & chr15:50241944-50266049 & 3.07157 & $5.00 E-05$ & Up \\
\hline ANKRD22 & chr10:88802729-88851975 & 2.85326 & $5.00 E-05$ & Up \\
\hline APOL4 & chr22:36189127-36204833 & 2.66818 & $5.00 E-05$ & Up \\
\hline TTC26 & chr7:139133743-139191986 & 2.42405 & $5.00 E-05$ & Up \\
\hline KRT1 & chr12:52674735-52680407 & 2.38486 & $5.00 E-05$ & Up \\
\hline SLC2A14 & chr12:7812511-7891196 & 2.37518 & $5.00 E-05$ & Up \\
\hline BATF2 & chr11:64987944-64997045 & 2.22325 & $5.00 E-05$ & Up \\
\hline LOC100996713 & chr1:143874742-143885954 & 2.21011 & Up \\
\hline
\end{tabular}




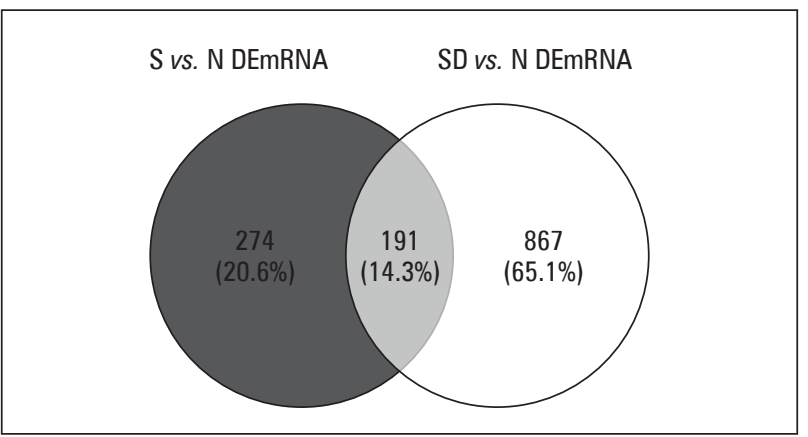

Figure 2. Venn diagram of DEGs between $S$ vs. $N$ and $S D$ vs. $N$. The purple circle represents the DEGs of $S$ vs. N. The yellow circle represents DEGs of SD vs. N

\section{Gene classification according to expression level}

In order to clarify the expression pattern of key genes in three groups ( $\mathrm{S}$ vs. N, SD vs. N, overlapping group and SD vs. S), we classified these genes into four groups according to the expression pattern: genes which significantly different expressed in $\mathrm{S}$ vs. $\mathrm{N}$ and $\mathrm{SD}$ vs. $\mathrm{N}$ but showed no different expression in SD vs. S group; genes which significantly different expressed in $\mathrm{S} v s . \mathrm{N}$ and SD vs. N and showed significantly different expression in $S D$ vs. S group; genes which showed different expression in S vs. $\mathrm{N}$ and SD vs. S group; genes which showed different expression in SD vs. $\mathrm{N}$ and $\mathrm{SD}$ vs. S group (Tab. 9).

\section{Identification of the nearby and co-expressed DEmRNAs of DElncRNAs}

Two DElncRNA-nearby targeted DEmRNA pairs (involved two DElncRNAs and two DEmRNAs) and three DElncRNA-nearby targeted DEmRNA pairs (involved three DElncRNAs and three DEmRNAs) were obtained in the $\mathrm{S}$ vs. $\mathrm{N}$ and $\mathrm{SD}$ vs. $\mathrm{N}$ group, respectively (Tab. 10). In addition, a total of $336 \mathrm{ln}$ cRNA-mRNA co-expression pairs were obtained in $\mathrm{S}$ vs. $\mathrm{N}$ group $(|\mathrm{r}|>0.95$ and $\mathrm{p}<0.05)$. The interaction network of lncRNAs and mRNAs in the $\mathrm{S} v \mathrm{~s}$. N group (Fig. 1A) showed that the LOC105369772 (degree = 56), LOC105369315 (degree = 32), LOC105369228 (degree $=21)$, and LIN00235 (degree $=21)$ were hub DElncRNAs with higher degree. Meanwhile, 2536 IncRNA-mRNA co-expression pairs were obtained in the SD vs. $N$ group $(|r|>0.95$ and $p<0.05)$. The interaction network of lncRNA-mRNA in the SD vs. N group (Fig. 1B) showed that the LOC102723540 $($ degree $=96)$, LOC105371058 $($ degree $=93)$, and LOC105377826 (degree $=87$ ) were hub DElncRNAs with higher degree. Several key DElncRNA-DEmRNAs were shared in both the $\mathrm{S}$ vs. N group and the SD vs. N

Table 6. Top 20 significantly differentially expressed lncRNAs in $S$ vs. $N$ group

\begin{tabular}{|c|c|c|c|c|}
\hline Gene & Locus & Log2 (fold change) & p value & Up/Down \\
\hline PSMD5-AS1 & chr9:120843041-120854373 & -1.85303 & 5.00E-05 & Down \\
\hline LOC105369772 & chr12:52625675-52630770 & 1.8639 & $5.00 \mathrm{E}-05$ & Up \\
\hline LOC101929866 & chr20:45178476-45191638 & 0.712603 & 0.0004 & Up \\
\hline LINC01002 & chr19:197015-202209 & -0.97745 & 5.00E-05 & Down \\
\hline LOC105369645 & chr12:8563194-8566073 & 0.770123 & 0.00055 & Up \\
\hline LOC102725068 & chr6:31479917-31494794 & -0.89235 & 0.0009 & Down \\
\hline LINC01279 & chr3:112596793-112601969 & -1.25572 & 0.0012 & Down \\
\hline FLVCR1-AS1 & chr1:212856603-212858138 & -1.26572 & 0.00225 & Down \\
\hline PAX8-AS1 & chr2:113215996-113278950 & -0.92159 & 0.00265 & Down \\
\hline LOC101928906 & chr9:41649583-41654873 & 1.03736 & 0.0006 & Up \\
\hline LOC105374445 & chr4:48269971-48288953 & 5.42782 & 0.0008 & Up \\
\hline LOC101929506 & chr10:79666864-79679237 & -0.61574 & 0.00315 & Down \\
\hline LOC105371058 & chr16:3077271-3087993 & 1.07842 & 0.00085 & Up \\
\hline LOC100499194 & chr2:113977668-114007310 & 1.20659 & 0.00095 & Up \\
\hline LOC105377997 & chr6:127663345-127685373 & -0.88753 & 0.0053 & Down \\
\hline LINC00211 & chr2:37826246-37875863 & 0.931827 & 0.0017 & Up \\
\hline SNHG11 & chr20:38446653-38450921 & 2.3711 & 0.00245 & Up \\
\hline LOC101927759 & chr6:3024790-3027424 & -0.92149 & 0.00935 & Down \\
\hline GLIDR & chr9:39803495-39810159 & 1.00066 & 0.00945 & Up \\
\hline LOC105378122 & chr6:167111806-167139141 & -0.91848 & 0.01145 & Down \\
\hline
\end{tabular}


A

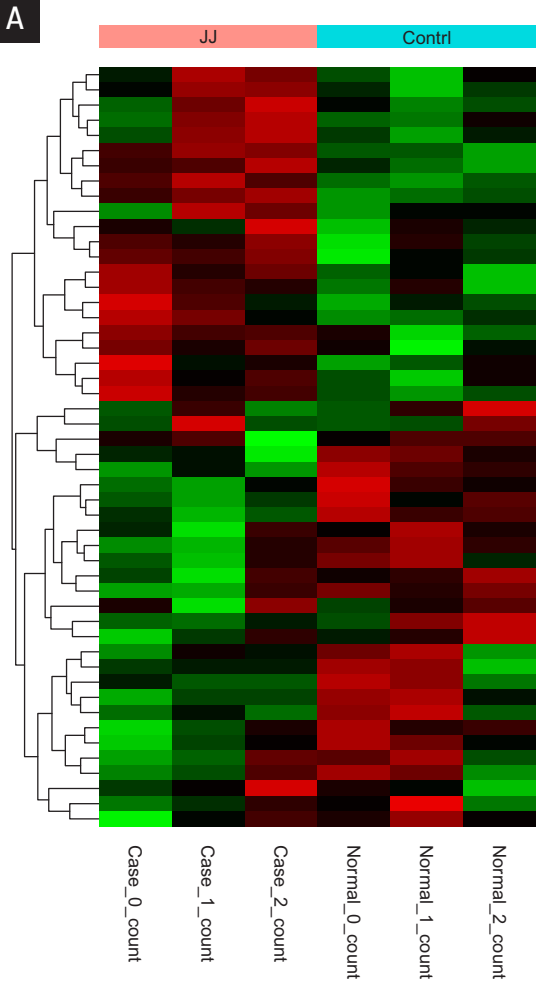

B

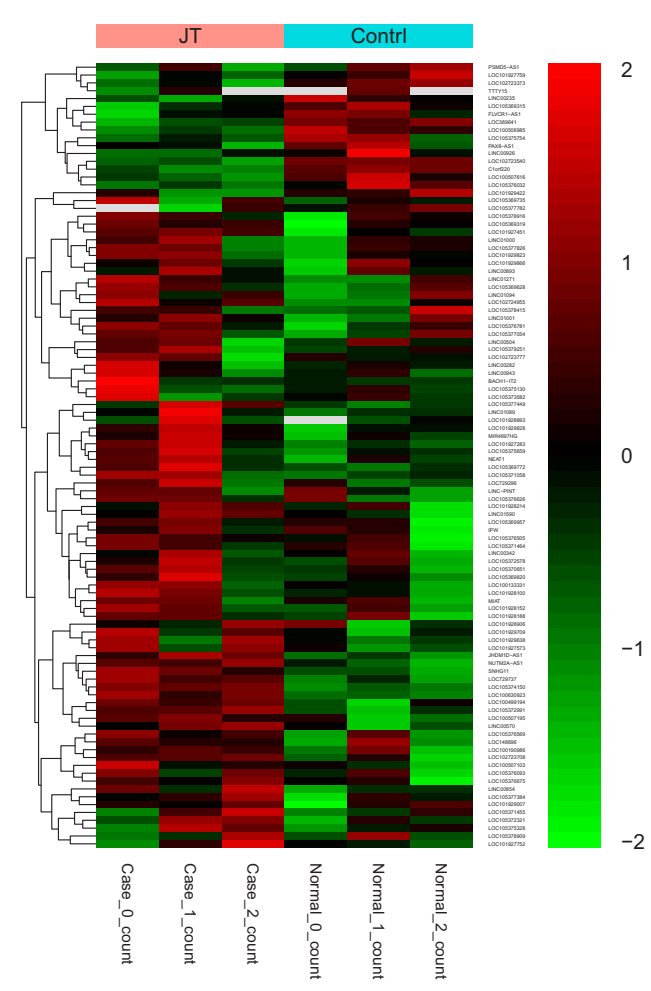

Figure 3. Hierarchical clustering analysis of top 100 DElncRNAs between $S$ and normal samples (A), SD and normal samples (B). Row and column represents DElncRNAs and samples, respectively. JJ — S group; JT - SD group

Table 7. Top 20 significantly differentially expressed lncRNAs in SD vs. $N$ group

\begin{tabular}{lcccc}
\hline Gene & Locus & Log2 (fold change) & p value & Up/Down \\
\hline LOC105374150 & chr3:148439991-148465791 & 2.10165 & $5.00 \mathrm{E}-05$ & Up \\
\hline LOC105369772 & chr12:52625675-52630770 & 1.72697 & $5.00 \mathrm{E}-05$ & Up \\
\hline LOC729737 & chr1:91168-267354 & 1.43622 & $5.00 \mathrm{E}-05$ & Up \\
\hline LOC100499194 & chr2:113977668-114007310 & 1.42705 & $5.00 \mathrm{E}-05$ & Up \\
\hline JHDM1D-AS1 & chr7:140177260-140179640 & 1.32196 & $5.00 \mathrm{E}-05$ & Up \\
\hline LOC105372321 & chr19:21444103-21464331 & 1.96597 & 0.00015 & Up \\
\hline LOC100190986 & chr16:21432002-21434455 & 0.737839 & 0.00015 & Up \\
\hline LOC100507616 & chr12:92466439-92488106 & -1.16349 & 0.00015 & Down \\
\hline LOC100133331 & chr1:722045-730351 & 1.12216 & Up \\
\hline LOC102723373 & chr16:53373492-53384259 & -1.27737 & 0.00035 & Down \\
\hline LOC105370651 & chr14:97705988-97802275 & 1.0367 & 0.00035 & Up \\
\hline PSMD5-AS1 & chr9:120843041-120854373 & -0.86208 & 0.00045 & Down \\
\hline LOC105372991 & chr22:30447958-30472047 & 1.96689 & 0.00075 & Up \\
\hline LOC105369315 & chr11:59084936-59106688 & -0.94107 & 0.00105 & Down \\
\hline FLVCR1-AS1 & chr1:212856603-212858138 & -1.41027 & 0.0017 & Down \\
\hline LOC105375754 & chr8:127664538-127670992 & -0.84974 & 0.0025 & Down \\
\hline PAX8-AS1 & chr2:113215996-113278950 & -0.81792 & 0.00655 & Down \\
\hline LOC105377782 & chr8:2199669-2206204 & -1.116 & 0.0067 & Down \\
\hline LOC389641 & chr8:23225220-23230926 & -1.05705 & 0.0085 & Down \\
\hline LOC102723540 & chr19:34850668-34860576 & -1.36983 & Down \\
\hline
\end{tabular}


Table 8. Significantly differentially expressed lncRNAs in SD vs. S group

\begin{tabular}{lcccc}
\hline Gene & Locus & Log2 (fold change) & p value & Up/Down \\
\hline PSMD5-AS1 & chr9:120843041-120854373 & 0.992632 & 0.0003 & Up \\
\hline LOC729737 & chr1:91168-267354 & 1.30899 & $5.00 \mathrm{E}-05$ & Up \\
\hline LOC105378415 & chr10:88061829-88104391 & 0.702821 & 0.0009 & Up \\
\hline LOC105374150 & chr3:148439991-148465791 & 1.67017 & 0.00045 & Up \\
\hline LOC105372321 & chr19:21444103-21464331 & 1.73257 & 0.0001 & Up \\
\hline LOC105369735 & chr12:40207309-40211449 & 1.48402 & 0.00065 & Up \\
\hline LOC105369319 & chr11:60159240-60164400 & 1.17253 & 0.0011 & Up \\
\hline LOC105369219 & chr20:1692887-1727569 & 1.36886 & 0.00105 & Up \\
\hline LOC101929638 & chr22:29180622-29205834 & 1.75921 & 0.0011 & Up \\
\hline LOC101929007 & chr19:21569901-21627976 & 1.38662 & $5.00 \mathrm{E}-05$ & Up \\
\hline LOC101928214 & chr2:87659750-87687161 & 1.12687 & 0.00035 & Up \\
\hline LINC01002 & chr19:197015-202209 & 1.04842 & $5.00 \mathrm{E}-05$ & Up \\
\hline JHDM1D-AS1 & chr7:140177260-140179640 & 1.17132 & $5.00 \mathrm{E}-05$ & Up \\
\hline LOC105377782 & chr8:2199669-2206204 & -1.4337 & 0.0011 & Down \\
\hline
\end{tabular}

group, including LOC105369772-KIR2DS4 and C4BPA, LOC105378122-KIR3DL2 and LOC100499194- CD79A.

\section{Functional analysis of DEmRNAs and IncRNA-mRNA co-expression pairs}

Top 20 clusters by GO analysis of DEmRNAs in the S vs. $\mathrm{N}$ group, SD vs. $\mathrm{N}$ group, and $\mathrm{S}$ vs. SD group are shown in Figure 2. Key DEmRNAs in the $\mathrm{S}$ vs. N group were significantly enriched in the following: peptide chain elongation ( $p=1.50713 \mathrm{E}-17)$, defence response to other organisms ( $p=5.96629 \mathrm{E}-16)$, and cytokine signalling in the immune system ( $p=7.44435 \mathrm{E}-15)$, while key DEmRNAs in the SD vs. $\mathrm{N}$ group were significantly enriched in the following: adaptive immune system ( $p=1.20789 \mathrm{E}-18)$, regulated exocytosis $(p=6.52941 \mathrm{E}-18)$, and formation of a pool of free $40 \mathrm{~S}$ subunits ( $p=7.85923 \mathrm{E}-14)$. The overlapping DEmRNAs in the $\mathrm{S}$ vs. $\mathrm{N}$ and $\mathrm{SD}$ vs. $\mathrm{N}$ group were enriched in the following: defence response to other organisms ( $\mathrm{p}=4.37832 \mathrm{E}-14$ ), immune regulatory interactions between a lymphoid and a non-lymphoid cell $(p=4.46184 \mathrm{E}-10)$ and cell killing ( $p=9.26847 \mathrm{E}-09)$. DEmRNAs in the SD vs. S group were significantly enriched in the following: eukaryotic translation elongation ( $\mathrm{p}=1.94389 \mathrm{E}-22)$, myeloid cell differentiation $(\mathrm{p}=2.18517 \mathrm{E}-16)$, and cellular protein catabolic process $(\mathrm{p}=3.30271 \mathrm{E}-14)$.

Differentially expressed genes in the $\mathrm{S}$ vs. N group were clustered into 19 pathways by KEGG analysis (Fig. 3A). Ribosome pathway ( $\mathrm{p}=1.52651 \mathrm{E}-12)$ enriched most genes. Differentially expressed genes in the SD vs. N group were clustered into 54 pathways (Fig. 3B). Among them, pathways in cancer $(\mathrm{p}=0.00176), \mathrm{NOD}-\mathrm{like}$ receptor signalling pathway $(p=2.51189 \mathrm{E}-07)$, and influenza A ( $p=3.98107 \mathrm{E}-07)$ enriched most genes. Overlapping DEmRNAs in the S vs. N and SD vs. N group were enriched in the following: natural killer cell-mediated cytotoxicity ( $p=6.30957 \mathrm{E}-09)$, graft-versus-host disease ( $p=6.30957 \mathrm{E}-07)$, and antigen processing and presentation ( $p=1.99526 \mathrm{E}-06)$ (Fig. 3C). Differentially expressed genes in the SD vs. S group were enriched in 34 pathways, among which, DEmRNAs in the SD vs. S group were significantly enriched in the following: ribosome ( $p=1 \mathrm{E}-14)$, HTLV-I infection $(p=0.000316228)$, and transcriptional misregulation in cancer ( $p=5.01187 \mathrm{E}-06)$ (Fig. 3D).

In addition, the top 20 clusters by GO analysis of DEmRNAs of co-expressed DElncRNAs in the $S$ vs. N group, $\mathrm{SD}$ vs. N group are shown in Figure 4. In GO analysis, co-expressed DEmRNAs of DElncRNAs in the $\mathrm{S}$ vs. $\mathrm{N}$ group were significantly enriched in the following: cytokine signalling in the immune system ( $p=1.39147 \mathrm{E}-11)$, peptide chain elongation ( $p=4.01217 \mathrm{E}-11)$, and response to virus ( $\mathrm{p}=3.08943 \mathrm{E}-10)$. In the $\mathrm{SD}$ vs. $\mathrm{N}$ group, co-expressed DEmRNAs of DElncRNAs were significantly enriched in the following: adaptive immune response ( $p=3.01114 \mathrm{E}-16)$, regulated exocytosis ( $\mathrm{p}=3.38002 \mathrm{E}-16)$, and platelet degranulation $(\mathrm{p}=3.22747 \mathrm{E}-11)$. In KEGG analysis, co-expressed DEmRNAs of DElncRNAs were enriched into 12 and 48 pathways in $\mathrm{S}$ vs. $\mathrm{N}$ and SD vs. N, respectively (Fig. 5).

\section{Discussion}

Key genes were identified in the top 20 differentially expressed mRNAs and lncRNAs in all groups ( $\mathrm{S}$ vs. N, 
Table 9. Classification of DEmRNAs in all groups

\begin{tabular}{|c|c|c|c|c|c|c|c|}
\hline Gene name & Shared genes & $\begin{array}{c}\text { p value } \\
\text { in SD vs. S }\end{array}$ & Up/Down & $\begin{array}{l}\text { p value } \\
\text { in S vs. } \mathbf{N}\end{array}$ & Up/Down & $\begin{array}{c}\text { p value } \\
\text { in SD vs. } \mathbf{N}\end{array}$ & Up/Down \\
\hline \multicolumn{8}{|c|}{ Shared genes that showed no different expression in SD vs. S } \\
\hline ARHGEF10 & Yes & 1 & Down & $5.00 \mathrm{E}-05$ & Down & $5.00 \mathrm{E}-05$ & Down \\
\hline IFI6 & Yes & 0.30125 & Up & 0.00335 & Up & $5.00 \mathrm{E}-05$ & Up \\
\hline IFIT1 & Yes & 0.47405 & Up & 0.0002 & Up & $5.00 \mathrm{E}-05$ & Up \\
\hline KIR2DS4 & Yes & 0.8401 & Down & $5.00 \mathrm{E}-05$ & Down & $5.00 \mathrm{E}-05$ & Down \\
\hline KIR3DL1 & Yes & 0.8715 & Down & $5.00 \mathrm{E}-05$ & Down & $5.00 \mathrm{E}-05$ & Down \\
\hline KIR3DL2 & Yes & 0.0916 & Down & $5.00 \mathrm{E}-05$ & Down & $5.00 \mathrm{E}-05$ & Down \\
\hline RAP1GAP & Yes & 0.3273 & Down & $5.00 \mathrm{E}-05$ & Down & $5.00 \mathrm{E}-05$ & Down \\
\hline KIR2DL1 & Yes & 0.75155 & Down & $5.00 \mathrm{E}-05$ & Down & 0.0001 & Down \\
\hline KIR2DL3 & Yes & 0.51745 & Down & $5.00 \mathrm{E}-05$ & Down & 0.00225 & Down \\
\hline \multicolumn{8}{|c|}{ Shared genes that showed different expression in SD vs. S } \\
\hline HDC & yes & $5.00 \mathrm{E}-05$ & Up & $5.00 \mathrm{E}-05$ & Down & 0.02025 & Up \\
\hline BATF2 & Yes & $5.00 \mathrm{E}-05$ & Up & $5.00 \mathrm{E}-05$ & Down & 0.0005 & Up \\
\hline ANK1 & yes & $5.00 \mathrm{E}-05$ & Up & 0.0221 & Up & $5.00 \mathrm{E}-05$ & Up \\
\hline LAIR2 & No & $5.00 \mathrm{E}-05$ & Down & $5.00 \mathrm{E}-05$ & Up & 0.5574 & / \\
\hline RPL26 & No & $5.00 \mathrm{E}-05$ & Down & $5.00 \mathrm{E}-05$ & Up & 0.40125 & / \\
\hline RPS3A & No & $5.00 \mathrm{E}-05$ & Down & $5.00 \mathrm{E}-05$ & Up & 0.46395 & / \\
\hline \multicolumn{8}{|c|}{ Different genes expression in S vs. $\mathrm{N}$ and SD vs. $\mathrm{N}$ group } \\
\hline SH2D1B & No & $5.00 \mathrm{E}-05$ & Down & $5.00 \mathrm{E}-05$ & Up & 0.6478 & I \\
\hline FCGBP & No & 0.0001 & Down & $5.00 \mathrm{E}-05$ & Up & 0.8163 & / \\
\hline RPL39 & No & 0.0001 & Down & $5.00 \mathrm{E}-05$ & Up & 0.51845 & / \\
\hline RPL23 & No & 0.0002 & Down & $5.00 \mathrm{E}-05$ & Up & 0.1052 & / \\
\hline SLC2A14 & No & $5.00 \mathrm{E}-05$ & Up & $5.00 \mathrm{E}-05$ & Down & 0.88125 & / \\
\hline GATA2 & No & $5.00 \mathrm{E}-05$ & Up & $5.00 \mathrm{E}-05$ & Down & 0.52595 & / \\
\hline GPR162 & No & $5.00 \mathrm{E}-05$ & Down & 0.30595 & / & $5.00 \mathrm{E}-05$ & Down \\
\hline \multicolumn{8}{|c|}{ Different genes expression in SD vs. S and SD vs. $\mathrm{N}$} \\
\hline ZNF683 & No & $5.00 \mathrm{E}-05$ & Down & 0.23495 & / & $5.00 \mathrm{E}-05$ & Down \\
\hline TCL1A & No & $5.00 \mathrm{E}-05$ & Down & 0.08845 & 1 & $5.00 \mathrm{E}-05$ & Down \\
\hline RPS26 & No & $5.00 \mathrm{E}-05$ & Down & 0.00565 & Up & $5.00 \mathrm{E}-05$ & Down \\
\hline RPS28 & No & $5.00 \mathrm{E}-05$ & Down & 0.5493 & 1 & 0.00015 & Down \\
\hline ANKRD22 & No & $5.00 \mathrm{E}-05$ & Up & 1 & 1 & $5.00 \mathrm{E}-05$ & Up \\
\hline APOL4 & No & $5.00 \mathrm{E}-05$ & Up & 1 & 1 & $5.00 \mathrm{E}-05$ & Up \\
\hline FAM46C & No & $5.00 \mathrm{E}-05$ & Up & 0.41555 & 1 & $5.00 \mathrm{E}-05$ & Up \\
\hline PNMA6A & NO & $5.00 \mathrm{E}-05$ & Up & 1 & 1 & 0.00045 & Up \\
\hline
\end{tabular}

Table 10. Nearby mRNAs of DElncRNAs in $S$ vs. N and SD vs. $N$

\begin{tabular}{|c|c|c|c|c|c|c|}
\hline \multirow[b]{2}{*}{ Chr } & \multicolumn{3}{|c|}{ IncRNA } & \multicolumn{3}{|c|}{ mRNA } \\
\hline & Symbol & Start-100kb & End $+100 \mathrm{~kb}$ & Symbol & Start & End \\
\hline \multicolumn{7}{|c|}{ S vs. N } \\
\hline chr6 & LOC105378122 & 167111706 & 167139241 & CCR6 & 167111806 & 167139141 \\
\hline chr6 & LOC102725068 & 31479817 & 31494894 & MICB & 31494880 & 31511124 \\
\hline \multicolumn{7}{|c|}{ SD vs. N } \\
\hline chr9 & LOC105376032 & 36833173 & 37036049 & PAX5 & 36833273 & 37035949 \\
\hline chr12 & LOC101928100 & 10363668 & 10410246 & KLRK1 & 10363768 & 10410146 \\
\hline chr1 & LOC105371464 & 159800380 & 159816357 & FCRL6 & 159800480 & 159816257 \\
\hline
\end{tabular}



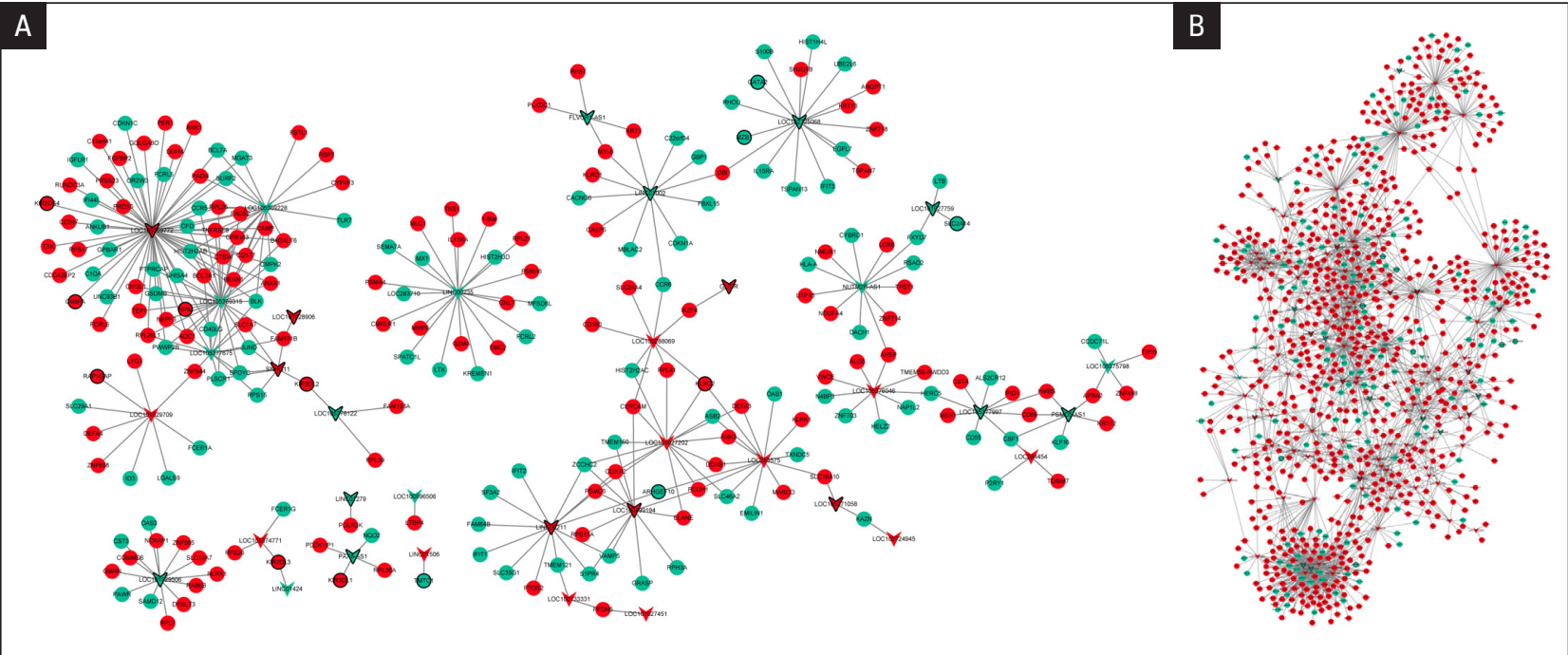

Figure 4. DElncRNA-DEmRNA co-expression network of $S$ vs. $N$ group $(\boldsymbol{A})$, in $S D$ ws. $N$ group $(\boldsymbol{B})$. The triangle and the circle represent DElncRNAs and DEmRNAs, respectively. Green and red colours represent down-regulation and up-regulation, respectively. The top10 down-/up-regulated DEmRNAs and DElncRNAs are represented with the black border

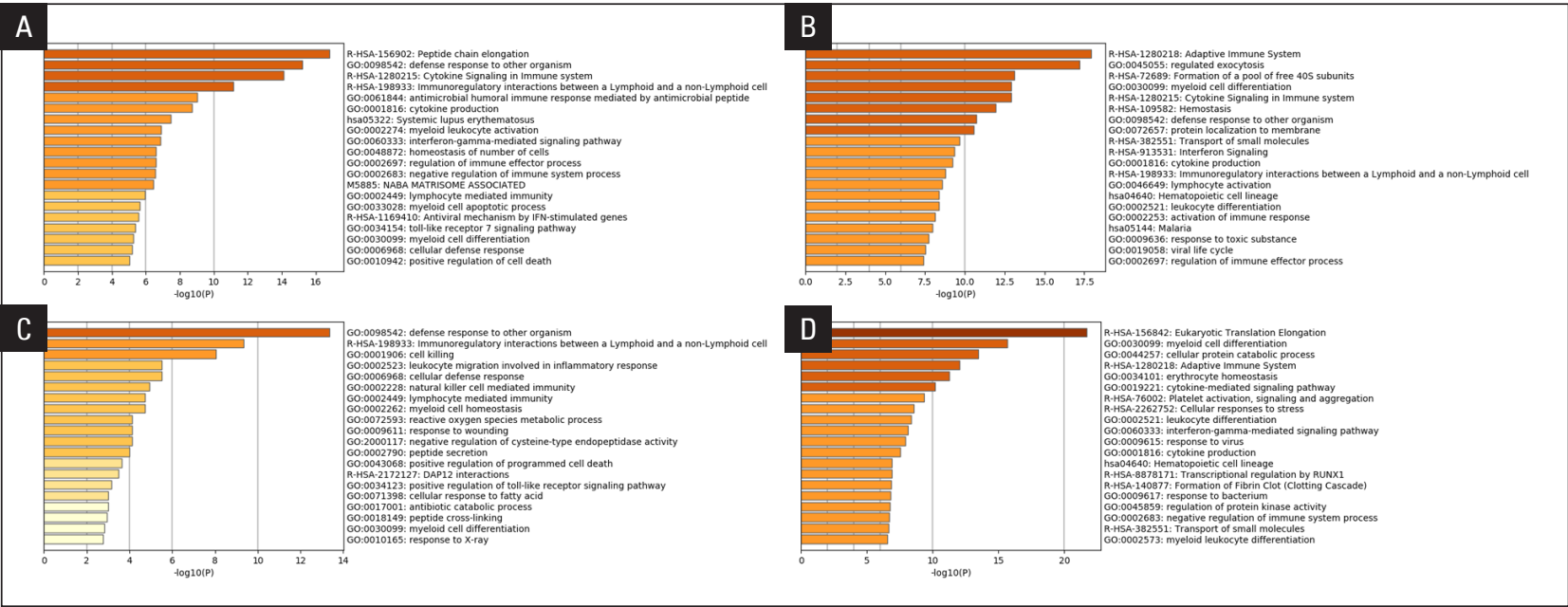

Figure 5. Top 20 significantly enriched GO terms in $S$ vs. $N$ group $(\boldsymbol{A}), S D$ vs. $N$ group $(\boldsymbol{B})$, overlapping DEmRNAs in $S$ and $S D$ $(C), S D$ vs. S group $(D)$. The Y-axis shows the description of GO terms and the X-axis represents $p$ value. The colour scale represents counts of DEmRNAs

$\mathrm{SD}$ vs. $\mathrm{N}$ and $\mathrm{S}$ vs. SD). Among these genes, several genes were deduced to be involved in $\mathrm{SCH}$, including LAIR2, PNMA6A, SFRP2, RAP1GAP, BATF2, and lncRNA- PAX8-AS1. According to previous studies, LAIR2 was increased in patients with autoimmune thyroid diseases while PNMA6A was verified to decrease in hypothyroid $[15,16]$. SFRP2 was a target of thyroid hormone receptor alpha1 [17], and RAP1GAP might function in thyroid cancer [18]. Notably, PAX8 was regarded a transcription factor in the developing and adult thyroid [19]. PAX8-AS1 was an antisense RNA to regulate PAX8, which was reported to inhibit cell cycle in vitro and associate with thyroid cancer [20,21].
We assumed shared genes that showed coincident expression in the $S$ and SD group were involved in SCH. In previous studies, ARHGEF10 was reported to be involved in atherosclerosis and hypertriglyceridaemia, both of which complicated with diabetes [22, 23]. IFI6 and IFIT1 were reported to be highly expressed in diabetes [24]. KIR3DL2, KIR2DL1, KIR3DL3, KIR2DS4, and KIR3DL1 belong to killer cell immunoglobulin-like receptors, which have been associated with diabetes [25]. A published study proposed that the genetic imbalance between KIRs and their HLA class 1 ligands might contribute to the pathogenesis of diabetes [26]. Notably, KIR3DL1 was co-expressed with PAX8-AS1 in our study. 


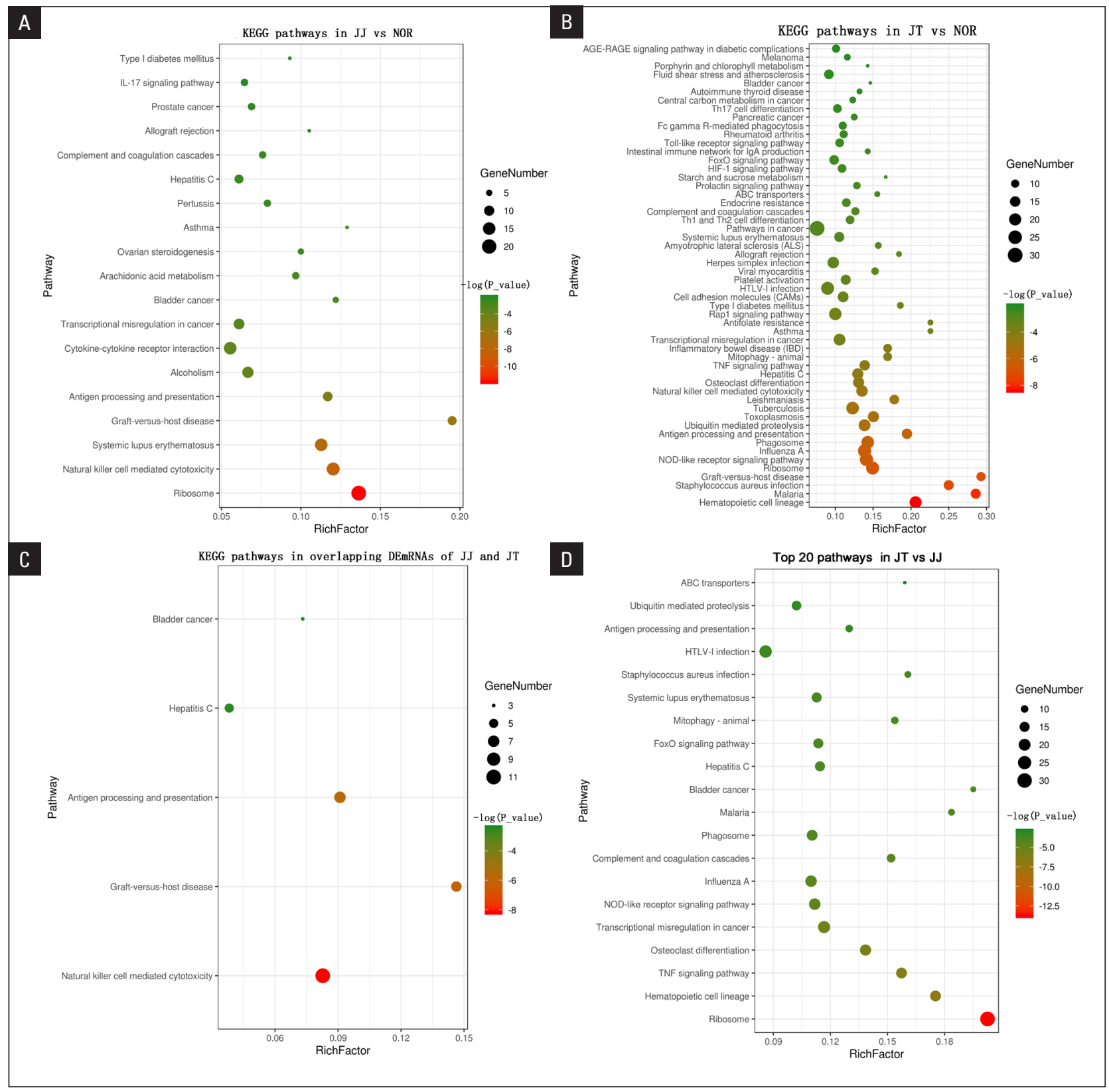

Figure 6. KEGG pathways in $S$ vs. $N$ group $(\boldsymbol{A}), S D$ vs. $N(\boldsymbol{B})$, overlapping DEmRNAs in $S$ and $S D(\boldsymbol{C})$, in $S D$ vs. $S$ group (D). The Y-axis shows KEGG pathways and the X-axis represents rich factor to show enrichment degree. The colour scale represents -log ( $p$-value), and the area scale represents counts of DEmRNAs

In addition, combining with functional enrichment analyses, pathways of shared genes (KIR3DL1) in both S vs. N group and SD vs. N group enriched were involved in type 2 diabetes, including natural killer cell-mediated cytotoxicity [27] and antigen processing and presentation [28]. Natural killer cells (a subset of lymphocytes) contribute to innate immunity. It is found that natural killer cell-mediated cytotoxicity is associated with both anti-thyroid peroxidase antibody and type 2 diabetes $[27,29]$. In addition, those genes involved in antigen processing and presentation are related to anti-thyroid peroxidase antibody and type 2 diabetes [29,30]. There- fore, we deduced that the prevalence of type 2 diabetes might be associated with subclinical hypothyroidism, and the regulation of PAX-AS1 on KIR3DL1 might function in this process. To explore whether high occurrence of type 2 diabetes existed in patients with subclinical hypothyroidism, we focused on genes that showed significantly different expression between the S and SD group. ANK1 showed significantly higher expression in the $\mathrm{SD}$ group than in the $\mathrm{S}$ and normal group, which is in accordance with previous report that high expression might contribute to type 2 diabetes susceptibility [31]. Conversely, APOL4, FAM46C and GPR162 showed 


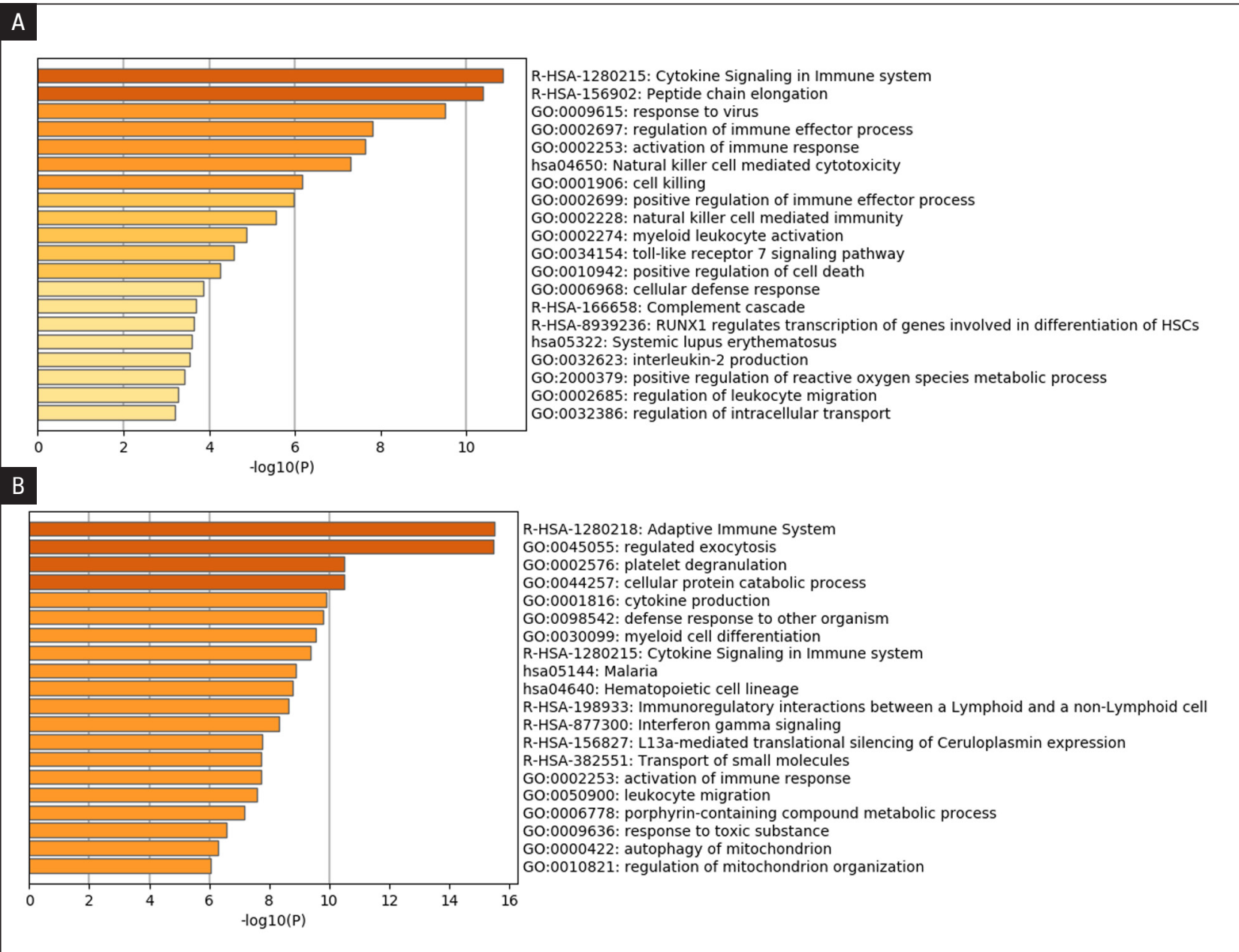

Figure 7. Top 20 significantly enriched GO terms of DEmRNA-DElncRNAs in $S$ vs. $N$ group $(\boldsymbol{A}), S D$ vs. $N$ group $(\boldsymbol{B})$. The Y-axis shows the description of GO terms and the X-axis represents $p$ value. The colour scale represents counts of DEmRNA-DElncRNAs

significantly different expression between SD and S group but showed no difference in expression between the $S$ and the normal group. According to the literature, APOL4 was reported to have a significant correlation with type 2 diabetes with hypertriglyceridaemia [32]. FAM46C was verified to highly express in both type 1 and type 2 diabetes [33]. GPR162 was proven as a receptor to be involved in the development of diabetes complications according to research in diabetic rats [34, 35]. The expression patterns of the above five genes were consistent with those in the literature about diabetes. Although the functional analysis of DEmRNAs in the SD vs. S group was performed, the regulatory pathway of type 2 diabetes in patients with $\mathrm{SCH}$ remained uncertain. Fortunately, key lncRNA was identified in the SD vs. S group. JHDM1D-AS1, as antisense RNA of JHDM1D, was involved in cancers by promoting angiogenesis and causing inflammation [36]. Moreover, JHDM1D belonged to histone demethylase as well as being homologous with JHDM2a. The loss of function of JHDM2a was verified to function in obesity and metabolic syndrome in a prior study in rats [37]. In our study, the up-regulation of JHDM1D-AS1 in the SD group might cause inflammation and metabolic syndrome. In addition, our study revealed that JHDM1D-AS1 was co-expressed with ANK1. We deduced that JHDM1D-AS1 regulated ANK1 epigenetics mechanisms to promote the occurrence of type 2 diabetes. However, several genes showed confusing expression patterns, which were up- or down-regulated in $\mathrm{S}$ vs. $\mathrm{N}$ but showed no difference between $\mathrm{SD}$ vs. $\mathrm{N}$, including up-regulated genes SH2D1B and ZNF683, and down-regulated genes SLC2A14. Therefore, more molecules like miRNAs and more samples should be excavated, and biology experiments should be performed to explore the molecular mechanism in $\mathrm{SCH}$ complicated with type 2 diabetes.

\section{Conclusion}

Several genes were deduced to function in $\mathrm{SCH}$, including LAIR2, PNMA6A, SFRP2, and IncRNA-PAX8-AS1, and we identified ANK1 and its co-expressed ln- 


\section{A}

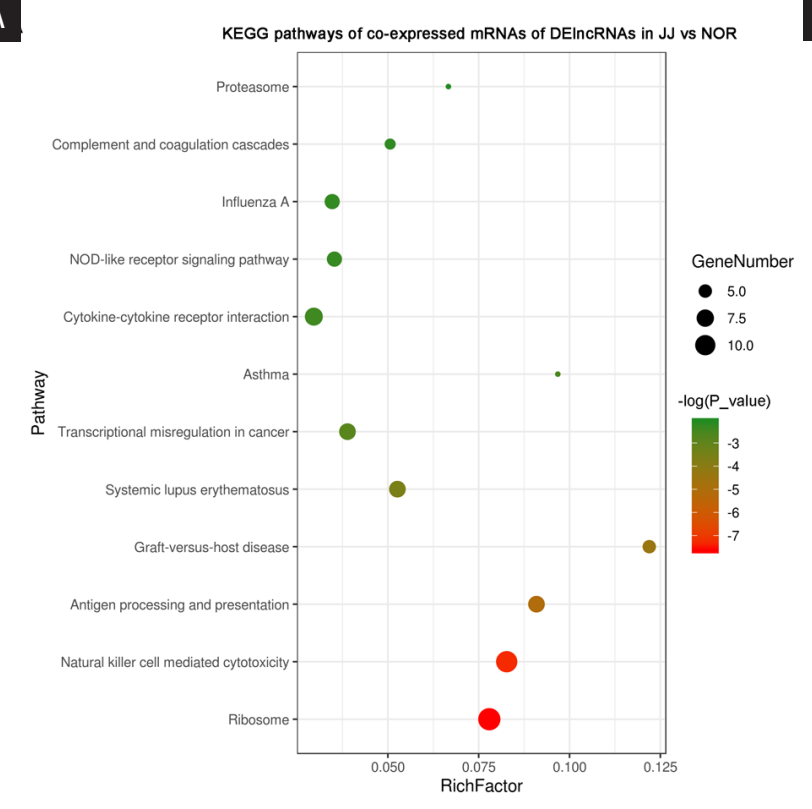

B

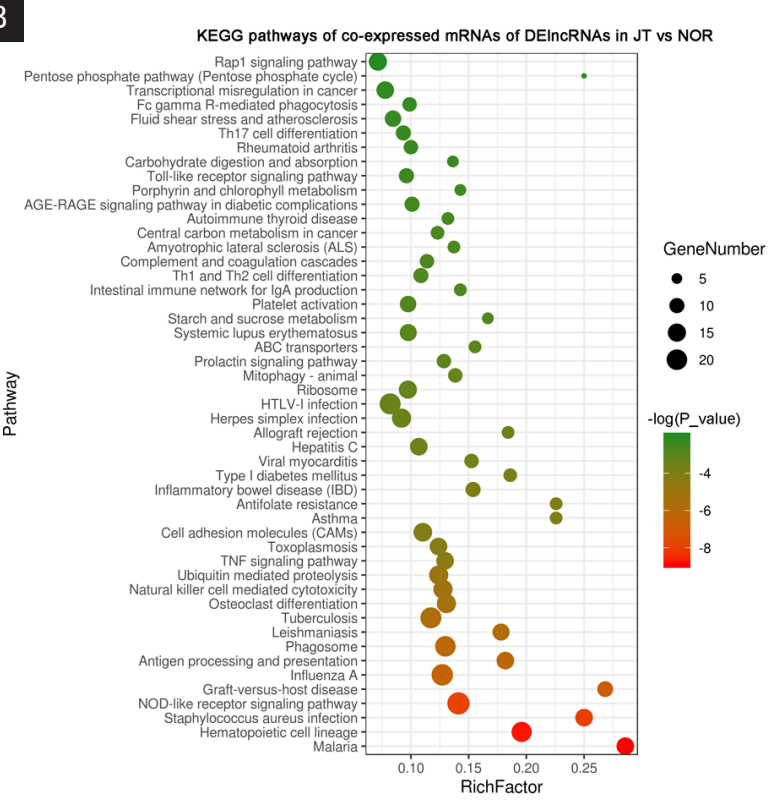

Figure 8. KEGG pathways enriched by DEmRNA-DElncRNAs in $S$ vs. $N$ group $(A), S D$ vs. $N(\boldsymbol{B})$. The Y axis shows KEGG pathways and the $X$-axis represents rich factor to show enrichment degree. The colour scale represents -log ( $p$-value), and the area scale represents counts of DEmRNA-DElncRNAs

cRNA-JHDM1D-AS1, which were deduced to function in SCH complicated with type 2 diabetes. The research initially proposed the theory that patients with $\mathrm{SCH}$ might have a higher risk of type 2 diabetes, and it provides a basis for further investigation of SCH complicated with type 2 diabetes. Our study suggested that molecular changes in identified lncRNAs and mRNAs may provide a novel clue in understanding the pathology of SCH and SCH complicated with diabetes. However, there are limitations to our study. Firstly, the sample size is small. Large numbers of blood samples of $S, S D$, and $N$ are further needed. Secondly, the potential mechanism of identified lncRNAs and mRNAs was not investigated. Some in vivo or in vitro experiments are also needed to explore the biological function mechanism of identified molecules. Thirdly, it would be very interesting to add more information to the research and perform the same transcriptome analysis in patients with type 2 diabetes and compare this analysis with the described results. Further research is needed.

\section{Acknowledgements}

None.

\section{Conflict of interest}

There are no conflicts of interest.

\section{Funding}

None.

\section{References}

1. Navarro PV, Pinilla EI, España AG, et al. Prevalence of hypothyroidism in major psychiatric disorders in hospitalised patients in Montserrat Hospital during the period March to October 2010. Rev Colomb Psiquiatr (English ed.). 2017; 46(3): 140-146, doi: 10.1016/j.rcpeng.2017.06.001, indexed in Pubmed: 28728797.

2. Canaris GJ, Manowitz NR, Mayor G, et al. The Colorado thyroid disease prevalence study. Arch Intern Med. 2000; 160(4): 526-534, doi: 10.1001/archinte.160.4.526, indexed in Pubmed: 10695693.

3. Gillett M. Subclinical Hypothyroidism: Subclinical Thyroid Disease: Scientific Review and Guidelines for Diagnosis and Management. Clin Biochem Rev. 2004; 25(3): 191-194, indexed in Pubmed: 1880829.

4. Surks MI, Ortiz E, Daniels GH, et al. Subclinical thyroid disease: scientific review and guidelines for diagnosis and management. JAMA. 2004; 291(2): 228-238, doi: 10.1001/jama.291.2.228, indexed in Pubmed: 14722150 .

5. Fatourechi V. Subclinical hypothyroidism and subclinical hyperthyroidism. Expert Rev Endocrinol Metab. 2010; 5(3): 359-373, doi: 10.1586/eem.10.2, indexed in Pubmed: 30861682 .

6. Auer R, Rodondi N. Relationship Between Subclinical Thyroid Dysfunction and Heart Failure and Mortality. In: Iervasi G, Pingitore A. ed. Thyroid and Heart Failure: From Pathophysiology to Clinics. Springer, Milan 2009: 167.

7. Loh HH, Lim LL, Yee A, et al. Association between subclinical hypothyroidism and depression: an updated systematic review and meta-analysis. BMC Psychiatry. 2019; 19(1): 12, doi: 10.1186/s12888-018-2006-2, indexed in Pubmed: 30621645.

8. Kung AW, Pang RW, Janus ED. Elevated serum lipoprotein(a) in subclinical hypothyroidism. Clin Endocrinol (Oxf). 1995; 43(4): 445-449, doi: 10.1111/j.1365-2265.1995.tb02616.x, indexed in Pubmed: 7586619.

9. Negro R, Stagnaro-Green A. Diagnosis and management of subclinical hypothyroidism in pregnancy. BMJ. 2014; 349: g4929, doi: 10.1136/bmj. g4929, indexed in Pubmed: 25288580.

10. Hecht A, Gershberg H. Diabetes mellitus and primary hypothyroidism. Metabolism. 1968; 17(2): 108-113, doi: 10.1016/0026-0495(68)90136-4, indexed in Pubmed: 5641743.

11. Cho JHo, Kim HoJ, Lee JHo, et al. Poor glycemic control is associated with the risk of subclinical hypothyroidism in patients with type 2 diabetes mellitus. Korean J Intern Med. 2016; 31(4): 703-711, doi: 10.3904/kjim.2015.198, indexed in Pubmed: 27271351.

12. Hon CC, Ramilowski JA, Harshbarger J, et al. An atlas of human long non-coding RNAs with accurate $5^{\prime}$ ends. Nature. 2017; 543(7644): 199-204, doi: 10.1038/nature21374, indexed in Pubmed: 28241135. 
13. Cabili MN, Trapnell C, Goff L, et al. Integrative annotation of human large intergenic noncoding RNAs reveals global properties and specific subclasses. Genes Dev. 2011; 25(18): 1915-1927, doi: 10.1101/gad.17446611, indexed in Pubmed: 21890647.

14. Kornienko AE, Guenzl PM, Barlow DP, et al. Gene regulation by the act of long non-coding RNA transcription. BMC Biol. 2013; 11: 59, doi: 10.1186/1741-7007-11-59, indexed in Pubmed: 23721193.

15. Alfadda AA, Benabdelkamel H, Masood A, et al. Differences in the Plasma Proteome of Patients with Hypothyroidism before and after Thyroid Hormone Replacement: A Proteomic Analysis. Int J Mol Sci. 2018; 19(1), doi: 10.3390/ijms19010088, indexed in Pubmed: 29301248.

16. Simone R, Pesce G, Antola P, et al. Serum LAIR-2 is increased in autoimmune thyroid diseases. PLoS One. 2013; 8(5): e63282, doi: 10.1371/journal.pone.0063282, indexed in Pubmed: 23691008.

17. Kress E, Rezza A, Nadjar J, et al. The frizzled-related sFRP2 gene is a target of thyroid hormone receptor alpha1 and activates beta-catenin signaling in mouse intestine. J Biol Chem. 2009; 284(2): 1234-1241, doi: 10.1074/jbc.M806548200, indexed in Pubmed: 19001373.

18. Zuo H, Gandhi M, Edreira MM, et al. Downregulation of Rap1GAP through epigenetic silencing and loss of heterozygosity promotes invasion and progression of thyroid tumors. Cancer Res. 2010; 70(4): 1389-1397, doi: 10.1158/0008-5472.CAN-09-2812, indexed in Pubmed: 20124489.

19. Poleev A, Fickenscher H, Mundlos S, et al. PAX8, a human paired box gene: isolation and expression in developing thyroid, kidney and Wilms' tumors. Development. 1992; 116(3): 611-623, indexed in Pubmed: 1337742

20. Placzkowski KA, Reddi HV, Grebe SKG, et al. The Role of the PAX8/PPARgamma Fusion Oncogene in Thyroid Cancer. PPAR Res. 2008; 2008: 672829, doi: 10.1155/2008/672829, indexed in Pubmed: 18989374.

21. Han J, Zhou W, Jia M, et al. Expression quantitative trait loci in long non-coding RNA PAX8-AS1 are associated with decreased risk of cervical cancer. Mol Genet Genomics. 2016; 291(4): 1743-1748, doi: 10.1007/s00438-016-1217-9, indexed in Pubmed: 27225188.

22. Matsushita T, Ashikawa K, Yonemoto K, et al. Functional SNP of ARHGEF10 confers risk of atherothrombotic stroke. Hum Mol Genet. 2010; 19(6): 1137-1146, doi: 10.1093/hmg/ddp582, indexed in Pubmed: 20042462.

23. de Toro-Martín J, Guénard F, Rudkowska I, et al. A common variant in ARHGEF10 alters delta- 6 desaturase activity and influence susceptibility to hypertriglyceridemia. J Clin Lipidol. 2018; 12(2): 311-320.e3, doi: 10.1016/j.jacl.2017.10.020, indexed in Pubmed: 29246731.

24. Lundberg M, Krogvold L, Kuric E, et al. Expression of Interferon-Stimulated Genes in Insulitic Pancreatic Islets of Patients Recently Diagnosed With Type 1 Diabetes. Diabetes. 2016; 65(10): 3104-3110, doi: 10.2337/db16-0616, indexed in Pubmed: 27422384.

25. Zhi D, Sun C, Sedimbi SK, et al. Killer cell immunoglobulin-like receptor along with HLA-C ligand genes are associated with type 1 diabetes in Chinese Han population. Diabetes Metab Res Rev. 2011; 27(8): 872-877, doi: 10.1002/dmrr.1264, indexed in Pubmed: 22069276.
26. van der Slik AR, Koeleman BPC, Verduijn W, et al. KIR in type 1 diabetes: disparate distribution of activating and inhibitory natural killer cell receptors in patients versus HLA-matched control subjects. Diabetes. 2003; 52(10): 2639-2642, doi: 10.2337/diabetes.52.10.2639, indexed in Pubmed: 14514651.

27. Li Lu, Pan Z, Yang Xi. Key genes and co-expression network analysis in the livers of type 2 diabetes patients. J Diabetes Investig. 2019; 10(4): 951-962, doi: 10.1111/jdi.12998, indexed in Pubmed: 30592156.

28. Russell MA, Redick SD, Blodgett DM, et al. HLA Class II Antigen Processing and Presentation Pathway Components Demonstrated by Transcriptome and Protein Analyses of Islet $\beta$-Cells From Donors With Type 1 Diabetes. Diabetes. 2019; 68(5): 988-1001, doi: 10.2337/db18-0686, indexed in Pubmed: 30833470.

29. Heon KS, Joo PY, Jin GM, et al. A genome-wide association study on thyroid function and anti-thyroid peroxidase antibodies in Koreans. Hum Mol Genet. 2014; 23(16): 4433-4442, doi: 10.1093/hmg/ddu145, indexed in Pubmed: 24722205.

30. Rasche A, Al-Hasani H, Herwig R. Meta-analysis approach identifies candidate genes and associated molecular networks for type- 2 diabetes mellitus. BMC Genomics. 2008; 9: 310, doi: 10.1186/1471-2164-9-310, indexed in Pubmed: 18590522

31. Yan R, Lai S, Yang Y, et al. A novel type 2 diabetes risk allele increases the promoter activity of the muscle-specific small ankyrin 1 gene. Sci Rep. 2016; 6: 25105, doi: 10.1038/srep25105, indexed in Pubmed: 27121283.

32. Duchateau PN, Movsesyan I, Yamashita S, et al. Plasma apolipoprotein L concentrations correlate with plasma triglycerides and cholesterol levels in normolipidemic, hyperlipidemic, and diabetic subjects. J Lipid Res. 2000; 41(8): 1231-1236, indexed in Pubmed: 10946010.

33. Collares CVA, Evangelista AF, Xavier DJ, et al. Transcriptome meta-analysis of peripheral lymphomononuclear cells indicates that gestational diabetes is closer to type 1 diabetes than to type 2 diabetes mellitus. Mol Biol Rep. 2013; 40(9): 5351-5358, doi: 10.1007/s11033-013-2635-y, indexed in Pubmed: 23657602.

34. Fox ER, Young JH, Li Y, et al. International Consortium for Blood Pressure Genome-wide Association Studies (ICBP-GWAS). Association of genetic variation with systolic and diastolic blood pressure among African Americans: the Candidate Gene Association Resource study. Hum Mol Genet. 2011; 20(11): 2273-2284, doi: 10.1093/hmg/ddr092, indexed in Pubmed: 21378095.

35. Ruiz-Hernández A, Sánchez-Muñoz F, Rodriguez J, et al. Expression of orphan receptors GPR22 and GPR162 in streptozotocin-induced diabetic rats. J Recept Signal Transduct Res. 2015; 35(1): 46-53, doi: 10.3109/1079 9893.2014.926926, indexed in Pubmed: 24937127.

36. Kondo A, Nonaka A, Shimamura T, et al. Long Noncoding RNA JHDM1D-AS1 Promotes Tumor Growth by Regulating Angiogenesis in Response to Nutrient Starvation. Mol Cell Biol. 2017; 37(18), doi: 10.1128/MCB.00125-17, indexed in Pubmed: 28652266.

37. Inagaki $\mathrm{T}$, Tachibana $\mathrm{M}$, Magoori $\mathrm{K}$, et al. Obesity and metabolic syndrome in histone demethylase JHDM2a-deficient mice. Genes Cells. 2009; 14(8): 991-1001, doi: 10.1111/j.1365-2443.2009.01326.x, indexed in Pubmed: 19624751. 